\title{
Influence of synthesized nano-ZnO on cure and physico- mechanical properties of SBR/BR blends
}

\author{
${\text { Madhuchhanda } \text { Maiti }^{1} \cdot \text { Ganesh C. Basak }^{1} \text { - Vivek K. Srivastava }}^{1}$. \\ Raksh Vir Jasra ${ }^{1}$
}

Received: 6 June 2016/Accepted: 7 November 2016/Published online: 17 November 2016

(c) The Author(s) 2016. This article is published with open access at Springerlink.com

\begin{abstract}
This study focuses on the synthesis of zinc oxide $(\mathrm{ZnO})$ nanoparticles by high temperature calcination as well as low-temperature hydrolysis methods and their efficiency as cure activator in styrene-butadiene rubber/ polybutadiene rubber blend. The synthesized nano- $\mathrm{ZnO}$ samples were characterized by means of X-ray diffraction, BET surface area and transmission electron microscopy. The synthesized nano-ZnO samples had wurtzite structure and average particle size in the ' $\mathrm{nm}$ ' range. $\mathrm{ZnO}$ nanoparticles, synthesized on sepiolite template, were of smallest particle size (maximum number of particles in the range of 7-12 $\mathrm{nm}$ ) and highest surface area $\left(104 \mathrm{~m}^{2} \mathrm{~g}^{-1}\right)$. Polyethylene glycol (PEG)-6000 coated $\mathrm{ZnO}$ nanoparticles had rod-like structure; average diameter of the rods was $50 \mathrm{~nm}$. In the case of PEG-coated $\mathrm{ZnO}$ containing compounds, optimum cure time of the blend was decreased by 5 min compared to that of standard rubber grade- $\mathrm{ZnO}$ containing compound (used as reference). Optimum cure time was lowered by $7-10 \mathrm{~min}$ in the case of synthesized nano- $\mathrm{ZnO}$ containing compounds compared to the reference $\mathrm{ZnO}$ based compound in presence of conventional filler, carbon black. It was also observed from ICP-OES analysis that the presence of very little amount of magnesium in one of the synthesized $\mathrm{ZnO}$ has noticeable impact on cure properties. PEG-coated $\mathrm{ZnO}$ increased the tensile strength of gum vulcanizates by $28 \%$ compared to the reference $\mathrm{ZnO}$, acting as nanofiller at 3 phr loading. The study of curing behavior in dynamic condition was carried
\end{abstract}

Ganesh C. Basak

ganesh.basak@ril.com

1 Reliance Technology Group, Vadodara Manufacturing Division, Reliance Industries Ltd., Vadodara, Gujarat 391346, India out using DSC. The results differ slightly from static curing except PEG modified nano- $\mathrm{ZnO}$. Use of $\mathrm{ZnO}$ nanoparticles could provide faster crosslinking, better reinforcement at lower concentration compared to reference $\mathrm{ZnO}$.

Keywords Nano-ZnO $\cdot \mathrm{SBR} \cdot \mathrm{BR} \cdot$ Curing $\cdot$ Cure properties

\section{Introduction}

The rubber industries, specifically tire industries, contribute significantly to economy of a nation where automobile industry is growing at a very fast pace. Improvement in quality and safety of rubber products can have significant impact on this industry $[1,2]$. Zinc oxide $(\mathrm{ZnO})$ is primarily used as an activator for sulfur vulcanization of rubbers. Besides, inclusion of $\mathrm{ZnO}$ in the rubber compound brings other benefits viz., reduction in heat build-up, improvement of abrasion resistance and heat resistance of the vulcanizates. Furthermore, its high thermal conductivity helps to dissipate local heat concentrations in rubber products. Zinc oxide is a necessary ingredient in rubber compounds for bonding rubber to reinforcing steel cord, etc. Besides improving the properties of vulcanized rubbers, $\mathrm{ZnO}$ also assists in the processing of uncured rubbers. $\mathrm{ZnO}$ is added to rubber formulation to reduce shrinkage of molded rubber products and maintain the cleanliness of molds [3].

The road transport emission of zinc due to tire wear is the main sources of zinc pollution after iron and steel production and non-ferrous metals manufacture. This arises from the zinc content ( $1 \mathrm{wt} \%)$ of the tire-tread material $[4,5]$. But some adverse environmental effects of zinc exposure have been reported. In view of the upcoming legislation and eco-labeling requirements for tires, it can be 
stated that it is desirable to keep the $\mathrm{ZnO}$ content in rubber compounds as low as possible.

In rubber industry, various kinds of vulcanization activators like $\mathrm{CaO}, \mathrm{MgO}, \mathrm{CdO}, \mathrm{CuO}, \mathrm{PbO}$ and $\mathrm{NiO}$ have been used in order replace conventional $\mathrm{ZnO}$ due to its toxic and fouling characteristics for aquatic flora and fauna. Although among the various activators studied, $\mathrm{MgO}$ shows most promising candidate in terms of activating properties in comparison to $\mathrm{ZnO}$ but maximum crosslinking can be achieved in the presence of $\mathrm{ZnO}$ only [6]. Moreover, few reports are also available that describe the effect of layered double hydroxide (LDH) on elastomeric materials in the place of $\mathrm{ZnO}$. According to the literature reports, $\mathrm{LDH}$ material can be used as an alternative cure activator in place of $\mathrm{ZnO}$ and stearic acid combo in the conventional cure package for the preparation of rubber composites, and simultaneously can provide a strong platform for reduction of $\mathrm{ZnO}$ level in elastomer vulcanizate system [7].

In another approach, the concentration of $\mathrm{ZnO}$ can be minimized if the efficiency of $\mathrm{ZnO}$ during vulcanization can be enhanced by the maximization of the contact between the $\mathrm{ZnO}$ particles and the accelerators in the compound. This contact is dependent on the size, shape, specific surface area and dispersibility of the $\mathrm{ZnO}$ particles. Nano-sized $\mathrm{ZnO}$ particles have been paid more attention for their unique properties, even though there are limited open literatures available on nano- $\mathrm{ZnO}$ as cure activators. $\mathrm{ZnO}$ nanoparticles were studied as a cure activator and curing agent in natural rubber (NR), nitrile rubber (NBR), carboxylated nitrile rubber (XNBR) and chloroprene rubber (CR) by Bhowmick and his coworkers [8-10]. Similarly, it was used as cure activator in NR and CR by Joseph et al. [11, 12]. Nanostructured zinc oxide was used in crosslinking of hydrogenated butadieneacrylonitrile elastomer and XNBR by Przybyszewska and Zaborski [13-15]. Guzman et al. synthesized mixed metal oxide nanoparticles of zinc and magnesium to reduce the $\mathrm{ZnO}$ levels in rubber compounds [16]. Heideman et al. studied the influence of nano- $\mathrm{ZnO}$ on the cure properties of solution styrene-butadiene rubber (SBR) and ethylene-propylenediene rubber [17]. Kim et al. investigated the effect of nano$\mathrm{ZnO}$ on the cure characteristics and mechanical properties of the silica-filled natural rubber/butadiene rubber compounds [18]. Jincheng and Yuehui studied the application of nano$\mathrm{ZnO}$ master-batch in SBR [19].

In our previous work, we have studied the effect of nano$\mathrm{ZnO}$ on the cure properties of polybutadiene rubber (BR) [20]. It was observed that the nano- $\mathrm{ZnO}$ reduces curing time and also enhances physico-mechanical as well thermal stability properties of butadiene rubber compound at lower concentration compared to the conventional micro- $\mathrm{ZnO}$. However, to the best of our knowledge, the effect of nano$\mathrm{ZnO}$ as cure activator has not yet been explored for SBR/BR rubber blend. In the open literature, it has already been reported that nano-zinc oxides are effective activators and reinforcing agents in rubber systems. The "little size effect," "surface effect" and "quantum effect" of nano$\mathrm{ZnO}$ governs the properties of the composites [21]. Although considerable amount of work has been done so far on the use of nano- $\mathrm{ZnO}$ in place of conventional $\mathrm{ZnO}$ as a cure activator and for enhancing the mechanical properties of elastomer, the study on SBR/BR-nano- $\mathrm{ZnO}$ composites is scarcely available in the literature [22]. In the tire industry, SBR/BR blend is of considerable importance as it is widely used in passenger car tire-tread compound. Hence, investigation of nanocomposite based on SBR/BR blends and nano$\mathrm{ZnO}$ would not only be providing valuable information but also have wide applications. Typically SBR/BR blend shows slower curing rate than other general purpose rubbers such as NR and BR [3]. Hence, it will be of interest to study the cure properties of this blend with nano- $\mathrm{ZnO}$.

In this work, we have studied the influence of morphology, specific surface area and dispersibility of $\mathrm{ZnO}$ nanoparticles on the static and dynamic vulcanization of SBR/BR blends. We have studied the effect of sepiolite template and 'eco-friendly' metal oxide, magnesium oxide $(\mathrm{MgO})$ on nano- $\mathrm{ZnO}$ in the crosslinking of the rubber blend. The influence of nano- $\mathrm{ZnO}$ on the properties of $\mathrm{SBR} / \mathrm{BR}$ vulcanizates in the absence as well as in the presence of conventional filler was also evaluated.

\section{Experimental}

\section{Materials}

Zinc nitrate $\left[\mathrm{Zn}\left(\mathrm{NO}_{3}\right)_{2} \cdot 6 \mathrm{H}_{2} \mathrm{O}\right]$ [molecular weight (M.W.) $297.48,98 \%$ purity], ammonium carbonate $\left[\left(\mathrm{NH}_{4}\right)_{2} \mathrm{CO}_{3}\right]$ (M.W. 157.13, 31\% purity), acetone (M.W. 58.08, 99.5\% purity), methanol (M.W. 32.04, 99.5\% purity), sodium hydroxide pellets (M.W. 40.00, 98\% purity), 1-octanol (M.W. 130.23, 99\% purity), Stearic acid (M.W. 284.48, $98 \%$ purity), sulfur powder (M.W. 32.06, 99\% purity), $N$ cyclohexyl-2-benzothiazole sulfenamide (CBS) (M.W. 264.42, 97\% purity), microcrystalline wax, magnesium oxide $(\mathrm{MgO})$ were procured from Labort Fine Chem. Pvt. Ltd., India. Standard rubber grade zinc oxide $(\mathrm{ZnO})$, used as reference (designated as SZ), was supplied by Labort Fine Chem. Pvt. Ltd., India. Polyethylene glycol-6000 (PEG) was obtained from Alfa Biochem, Greece. Zinc acetate dihydrate $\left[\mathrm{Zn}\left(\mathrm{CH}_{3} \mathrm{COO}\right)_{2} \cdot 2 \mathrm{H}_{2} \mathrm{O}\right]$ (M.W. 219.50, 98.5\% purity) and Oxalic acid (M.W. 126.07, 99.8\% purity) were procured from S. D. Fine Chem. Ltd., India. $N$ (1,3-dimethyl butyl)- $N^{\prime}$-phenyl-p-phenylenediamine (6PPD) was obtained from John Baker Inc., USA. Polybutadiene rubber (BR; Cisamer $01 ; \mathrm{ML}_{1+4}$ at $100{ }^{\circ} \mathrm{C}=45$; cis-content $96 \%$ ) was collected from 
Reliance Industries Ltd., India. Styrene-butadiene rubber (SBR 1502; $\mathrm{ML}_{1+4}$ at $100{ }^{\circ} \mathrm{C}=48$ ) was supplied by Japan Synthetic Rubber, Japan. Sepiolite (Pangel S9) was generously supplied by Tolsa, Spain. Carbon black (N330) was procured from Philips Carbon Black Ltd., India.

\section{Preparation of nano-ZnO}

Nano-ZnO was synthesized by high temperature calcination as well as low-temperature hydrolysis methods. The typical procedures are described below.

\section{Method-1 [9]}

$\mathrm{Zn}\left(\mathrm{NO}_{3}\right)_{2} \cdot 6 \mathrm{H}_{2} \mathrm{O}$ and ammonium carbonate $\left(\mathrm{NH}_{4}\right)_{2} \mathrm{CO}_{3}$ were, respectively, dissolved in distilled water at a concentration of 1.0 M. Zinc nitrate solution was then slowly dropped into the vigorously stirred $\left(\mathrm{NH}_{4}\right)_{2} \mathrm{CO}_{3}$ solution with molar ratio of $2: 1$ to prepare the precursor. A white precipitate occurred immediately on mixing of the two solutions. Stirring was done for $3 \mathrm{~h}$ to have complete precipitation. The white precipitate thus obtained was filtered and repeatedly washed with distilled water to remove impurities and dried at $105^{\circ} \mathrm{C}$ for $6 \mathrm{~h}$. Calcination of the dried sample was carried out at $450{ }^{\circ} \mathrm{C}$ in a muffle furnace. The sample thus obtained is designated as $\mathrm{Z} 1$.

\section{Method-2 [23]}

$0.1 \mathrm{M}$ aqueous solution of oxalic acid was added to $0.1 \mathrm{M}$ aqueous solution of $\mathrm{Zn}\left(\mathrm{CH}_{3} \mathrm{COO}\right)_{2} \cdot 2 \mathrm{H}_{2} \mathrm{O}$ and the solution was stirred for $4 \mathrm{~h}$. The white precipitates thus obtained were filtered and washed with acetone and distilled water to remove impurities and dried at $120{ }^{\circ} \mathrm{C}$ for $6 \mathrm{~h}$. The dried sample was calcined at $450{ }^{\circ} \mathrm{C}$ in a muffle furnace to remove $\mathrm{CO}$ and $\mathrm{CO}_{2}$ from the compound. The sample is designated as $\mathrm{Z} 2$.

\section{Method- 3 [24]}

The solution of $\mathrm{Zn}\left(\mathrm{CH}_{3} \mathrm{COO}\right)_{2} \cdot 2 \mathrm{H}_{2} \mathrm{O}(0.1 \mathrm{M})$ was prepared in $50 \mathrm{ml}$ methanol under stirring. $25 \mathrm{ml}$ of $\mathrm{NaOH}$ $(0.3 \mathrm{M})$ solution, prepared in methanol, was mixed with above solution under continuous stirring to get the $\mathrm{pH}$ of reactants between 8 and 11. These solutions were transferred into a Teflon lined sealed stainless steel autoclave and maintained at $150{ }^{\circ} \mathrm{C}$ for $12 \mathrm{~h}$ under autogenous pressure. It was then allowed to cool naturally to room temperature. After the reaction was complete, the resulting white solid product was washed with methanol, filtered and then dried in a laboratory oven at $100{ }^{\circ} \mathrm{C}$. The sample is designated as Z3.
Method-4 [20]

Equivalent volume of $\mathrm{Zn}\left(\mathrm{CH}_{3} \mathrm{COO}\right)_{2} \cdot 2 \mathrm{H}_{2} \mathrm{O}(0.5 \mathrm{M})$ and sodium hydroxide $(1.5 \mathrm{M})$ were mixed to obtain a solution A. $2.5 \mathrm{~g}$ of PEG-6000 was dissolved in $10 \mathrm{ml}$ of water to obtain solution B. The solution B was then added into solution A to obtain solution C. $50 \mathrm{ml}$ of 1-octanol was added to solution $\mathrm{C}$ under stirring at room temperature to obtain solution D. Then solution D was transferred to Teflon lined stainless steel autoclave which was then maintained at $180{ }^{\circ} \mathrm{C}$ for $4 \mathrm{~h}$ under autogenous pressure. The $\mathrm{ZnO}$ powder was obtained after filtering, washing and drying in oven at $120{ }^{\circ} \mathrm{C}$. The sample is designated as Z4.

\section{Method-5}

The solution of $\mathrm{Zn}\left(\mathrm{CH}_{3} \mathrm{COO}\right)_{2} \cdot 2 \mathrm{H}_{2} \mathrm{O}(0.1 \mathrm{M})$ was prepared in $50 \mathrm{ml}$ methanol under stirring. $25 \mathrm{ml}$ of $\mathrm{NaOH}$ $(0.3 \mathrm{M})$ solution, prepared in methanol, was mixed with above solution under continuous stirring to get the $\mathrm{pH}$ of reactants between 8 and 11 , and then $4 \mathrm{~g}$ of sepiolite was added with vigorous stirring. It was then transferred into a Teflon lined sealed stainless steel autoclave and maintained at $150{ }^{\circ} \mathrm{C}$ for $12 \mathrm{~h}$ under autogenous pressure. Subsequently, it was allowed to cool naturally to room temperature. After the reaction was complete, the resulting white solid product was washed with methanol, filtered and then dried in a laboratory oven at $100{ }^{\circ} \mathrm{C}$. The sample is designated as Z5.

\section{Method-6}

$0.1 \mathrm{M}$ solution of $\mathrm{Zn}\left(\mathrm{CH}_{3} \mathrm{COO}\right)_{2} \cdot 2 \mathrm{H}_{2} \mathrm{O}$ in $50 \mathrm{ml}$ methanol was prepared. To this solution, $0.5 \mathrm{~mol}$ of $\mathrm{MgO}$ was added. $25 \mathrm{ml}$ of $\mathrm{NaOH}(0.3 \mathrm{M})$ solution, prepared in methanol, was mixed with above solution under continuous stirring to get the $\mathrm{pH}$ of reactants between 8 and 11. After that it was transferred into Teflon lined sealed stainless steel autoclave and maintained at $150{ }^{\circ} \mathrm{C}$ for $12 \mathrm{~h}$ under autogenous pressure. It was then allowed to cool naturally to room temperature. After the completion of the reaction, resulting white solid products were washed with methanol, filtered and dried in a laboratory oven at $100{ }^{\circ} \mathrm{C}$. The sample is designated as Z6.

\section{Characterization of zinc oxide particles}

\section{$X$-ray diffraction (XRD)}

X-ray diffraction analysis was done using X-ray diffractometer, Rigaku "Mini flex" model in the range of 10 to $80^{\circ}(=2 \theta)$. The zinc oxide powder was deposited on the sample holder uniformly. 
Brunauer Emmet Teller (BET) surface area measurement

BET surface area determination was done from $\mathrm{N}_{2}$ adsorption data measured at $77.4 \mathrm{~K}$ using micromeriticsASAP-2020 instrument. The samples were activated at $200{ }^{\circ} \mathrm{C}$ for $20 \mathrm{~min}$ under vacuum $(10 \mathrm{mmHg})$ prior to measurements. Five point BET surface area and total pore volume were measured. The average of five reading is reported here.

\section{Transmission electron microscopy (TEM)}

Morphology of different $\mathrm{ZnO}$ samples was investigated by transmission electron microscopy (TEM) (JEOL 2010) having $\mathrm{LaB}_{6}$ filament, operating at an accelerating voltage of $200 \mathrm{kV}$. ZnO powder samples were dispersed by ultrasonication in acetone for $30 \mathrm{~min}$. A copper grid was immersed in and taken out of the suspension and dried at room temperature. Image analysis of the microphotographs was performed using UTHSCSA Image Tool for Windows Version 3.00. It was used to determine the particle size distribution.

\section{Differential scanning calorimetry (DSC)}

Cure-studies were done using differential scanning calorimetric analysis. It was carried out using modulated DSC (DSC 2910, TA Instruments, USA). The samples were heated from ambient temperature to $250{ }^{\circ} \mathrm{C}$ (at $5{ }^{\circ} \mathrm{C} \mathrm{min}{ }^{-1}$ heating rate) in air. $5 \mathrm{mg}$ of each sample was taken for the measurement. The error limit in the 'weighing measurements' was within $\pm 5 \%$.

\section{Elemental analysis}

Elemental analysis was done using a Perkin Elmer (Model: Optima 4300 DV) inductively coupled plasma-optical emission spectroscopy (ICP-OES).

\section{Scanning electron microscopy (SEM)}

SEM samples were fractured in liquid nitrogen immersion and mounted with carbon tape wrapping. The images were studied with a Nova NanoSEM 650 instrument, FEI, USA, operating at 1 and $10 \mathrm{kV}$ for the micro and synthesized nano-ZnO samples, respectively.

\section{Preparation of rubber composites}

\section{Compounding and vulcanization}

$\mathrm{ZnO}$ was mixed with rubber by melt mixing method using Brabender Plasticorder (PL2000, Germany) internal mixer (volume $50 \mathrm{~cm}^{3}$ ) for $3 \mathrm{~min}$ at $80{ }^{\circ} \mathrm{C}$ and $60 \mathrm{rpm}$. The formulation is given in Table 1 . It was chosen as a typical tire-tread formulation. Amount of $\mathrm{ZnO}$ used $(0.5,1.5$ and 3 phr) was lower than that used ( 5 phr) in the conventional formulations. The sample was then passed through a cold two roll open mixing mill at a friction ratio 1:1.2. The curing studies were followed with an Oscillating Disc Rheometer (ODR-2000, FLEXSYS) at $145^{\circ} \mathrm{C}$ temperature and oscillating arc of $3^{\circ}$ for $1 \mathrm{~h}$. The samples were then compression molded at $145^{\circ} \mathrm{C}$ at optimum cure time.

\section{Physico-mechanical properties of rubber composites}

Tensile test

Tensile test of the sample was carried out according to ASTM D412-98a on dumbbell shaped specimens using Instron 3367 universal testing machine at ambient temperature at a crosshead speed of $500 \mathrm{~mm} \mathrm{~min}^{-1}$. Average of five samples is reported here.

\section{Hardness}

Hardness of each composition was obtained using Shore A Durometer tester as per ASTM D 2240-97.

\section{Volume fraction of rubber $\left(V_{r}\right)$ and crosslink density}

The cured samples were immersed in toluene for $72 \mathrm{~h}$ at $25{ }^{\circ} \mathrm{C}$ temperature. The volume fraction of rubber in the swollen gel, at equilibrium swelling, was calculated using Eq. (1):

$V_{\mathrm{r}}=\frac{(\mathrm{D}-\mathrm{FT}) \rho_{r}^{-1}}{(\mathrm{D}-\mathrm{FT}) \rho_{\mathrm{r}}^{-1}+A_{0} \rho_{\mathrm{s}}^{-1}}$,

where $D$ Deswollen weight, $F$ weight fraction of the insoluble component, $T$ initial weight of the test specimen, $\rho_{\mathrm{r}}$ density of rubber, $0.89 \mathrm{~g} \mathrm{~cm}^{-3}, \rho_{\mathrm{s}}$ density of solvent, $0.86 \mathrm{~g} \mathrm{~cm}^{-3}, A_{0}$ amount of solvent absorbed.

Further, the crosslink density, $\frac{1}{2 M_{\mathrm{C}}}$, in mol g ${ }^{-1}$ of rubber hydrocarbon was calculated using the Flory-Rehner Eq. (2):

$-\left[\ln \left(1-V_{\mathrm{r}}\right)+V_{\mathrm{r}}+\chi V_{\mathrm{r}}^{2}\right]=\frac{\rho_{\mathrm{r}} V\left(V_{\mathrm{r}}^{1 / 3}-V_{\mathrm{r}} / 2\right)}{2 M_{\mathrm{C}}}$,

$\chi$ Flory-Huggins interaction parameter, 0.46 for BRtoluene system [25], $V$ molar volume of swelling solvent, toluene, $M_{\mathrm{C}}$ number average molecular weight of the chain between two crosslinks. 


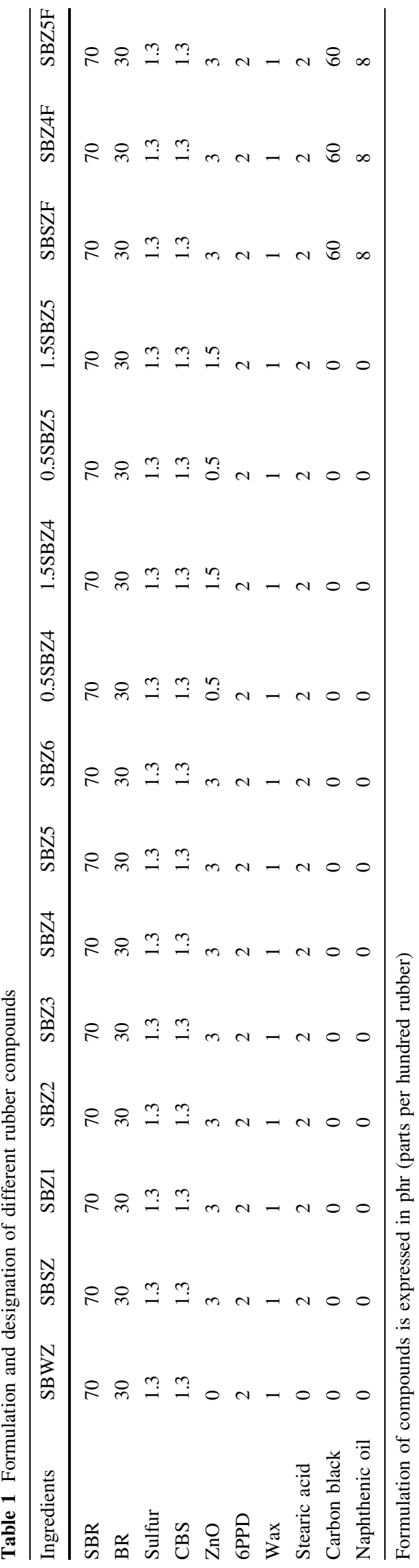

\section{Results and discussion}

\section{Characterization of nano- $\mathrm{ZnO}$}

$X R D$

Figure 1 shows the XRD patterns of different zinc oxide $(\mathrm{ZnO})$ samples. The sharp intense peaks, confirming the good crystalline nature of synthesized $\mathrm{ZnO}$, correspond to (100), (002), (101), (102), (110), (103), (200), (112), (201) and (004) planes. All of the indexed peaks in the obtained diffractograms match with that of the bulk ZnO (JCPDS card \# 79-0207) which confirm that the synthesized samples are of wurtzite hexagonal structure [26]. Any other peak related to impurities was not detected in the diffractogram within the detection limit of the XRD. Absence of any extra peak in the diffractograms of final products indicates the purity of the products. In Z5, additional peaks can be observed, other than the earlier mentioned peaks for $\mathrm{ZnO}$. These are for $(060),(131)$ [at $\left.20^{\circ}\right],(260)$ [at $24^{\circ}$ ] and $(080,331)$ planes [at $27^{\circ}, 28^{\circ}$ ] of sepiolite clay [27]. It proves that $\mathrm{ZnO}$ particles are formed on sepiolite without distorting the crystal structure of either material.

The average crystal size was calculated by Scherrer Eq. 28]:

$L=\frac{K \lambda}{\beta \cos \theta}$,

where, $\beta$ is the full-width at half maximum (FWHM) of the peak corresponding to (100) plane, $K$ is a constant (0.89), $\lambda$ is the incident wavelength of $\mathrm{CuK}_{\alpha}$ radiation $(\lambda=0.154 \mathrm{~nm}), L$ is the crystallite size, and $\theta$ is the diffraction angle at a certain crystal plane.

The average crystallite size of Z1, Z2, Z3, Z4, Z5 and Z6 was calculated using Eq. (3) and was found to be 23, 20, 18, 27,27 and $16 \mathrm{~nm}$, respectively. It should be noted that crystallite size is assumed to be the size of a coherently diffracting domain. It is not necessarily the same as particle size [28].

\section{BET surface area}

BET surface area of different prepared nano- $\mathrm{ZnO}$ is reported in Table 2. Surface area and pore volume both increase in the synthesized $\mathrm{ZnO}$ samples compared to the reference one. Highest surface area and pore volume can be observed in the case of $\mathrm{Z5}$. This could be due to dispersion of $\mathrm{ZnO}$ particles on the fibrous sepiolite template surface. For the same sample, smallest particle size was also observed through TEM (Fig. 2e). So the surface area results corroborate well with the microscopic study. The sample Z4 shows minimum surface area among the synthesized samples, as it is coated with PEG. The organic coating of PEG resists the nitrogen to be absorbed on the surface of $\mathrm{ZnO}$ particles. 
Fig. 1 X-ray diffractogram of the different zinc oxide samples

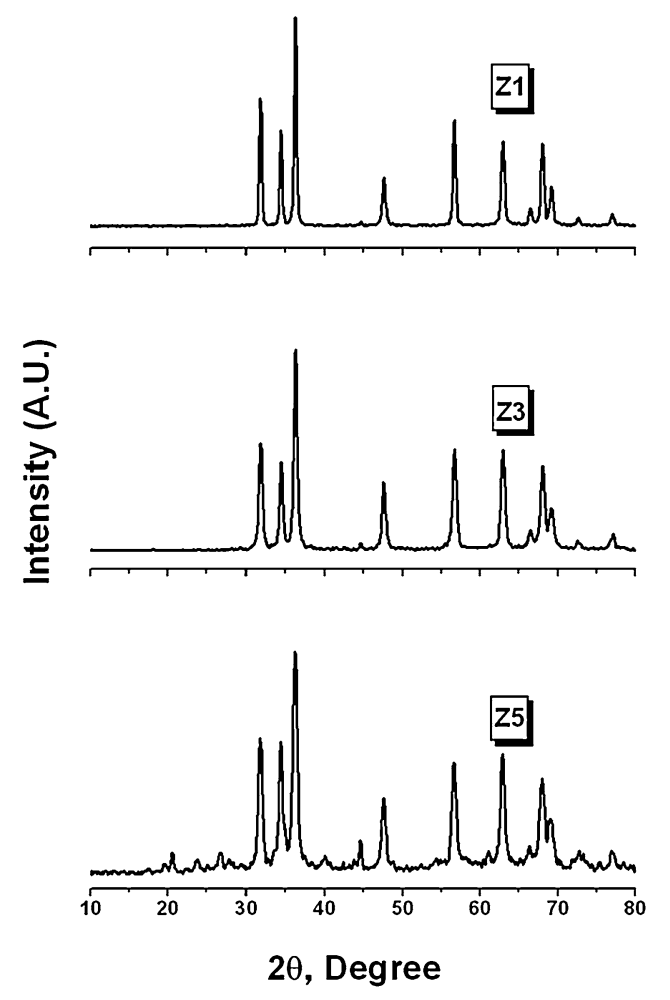

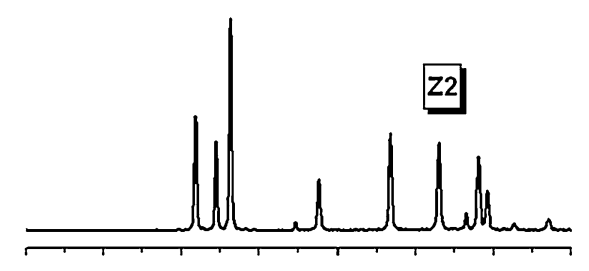
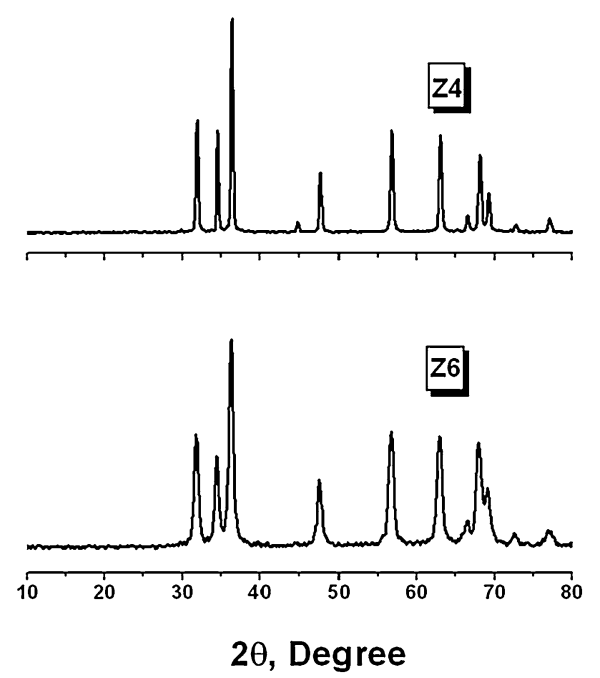

Table 2 Crystallite size of different zinc oxide samples

\begin{tabular}{lll}
\hline Sample & $\begin{array}{l}\text { FWHM of (100) } \\
\text { plane (degree) }\end{array}$ & $\begin{array}{l}\text { Average crystallite } \\
\text { size }(\mathrm{nm})\end{array}$ \\
\hline $\mathrm{Z1}$ & 0.3444 & 23 \\
$\mathrm{Z2}$ & 0.3936 & 20 \\
$\mathrm{Z3}$ & 0.4428 & 18 \\
$\mathrm{Z4}$ & 0.2952 & 27 \\
Z5 & 0.2952 & 27 \\
Z6 & 0.4920 & 16 \\
\hline
\end{tabular}

TEM

Figure 2a-f portrays TEM photo-micrographs of different zinc oxide $(\mathrm{ZnO})$ samples. TEM image exhibits the morphology of synthesized particles to be in nano region. Samples Z1, Z2, Z3, Z5 and Z6 show hexagonal structure. The particle size distribution curves for these samples are shown in Fig. 3. It shows that for Z1, maximum particles are in the range of $26-50 \mathrm{~nm}$; for $\mathrm{Z} 2$, it is also in the range of $26-50 \mathrm{~nm}$ and for $\mathrm{Z3}$, it is in the range of $15-28 \mathrm{~nm}$. The sample $\mathrm{Z} 4$ evinces rod-like structures grown on PEGsheets. The average rod diameter is $\sim 50 \mathrm{~nm}$. These nanorods are of 100-200 $\mathrm{nm}$ in length. Z5 exhibits an interesting morphology; it consists of smallest $\mathrm{ZnO}$ particles. Figure 2e infers that $\mathrm{ZnO}$ nanoparticles are grown on long bundles of sepiolite nanofibers. The $\mathrm{ZnO}$ particles are very small in size; most of the particles are in $7-12 \mathrm{~nm}$ range.

Sample Z6 has maximum particles in the range of $10-18 \mathrm{~nm}$.

\section{Application of synthesized nano-ZnO}

\section{Cure properties}

The effect of synthesized nano- $\mathrm{ZnO}$ as cure activator has been studied on SBR/BR blend. A representative rheographic profile of SBR/BR blends at $145^{\circ} \mathrm{C}$ is shown in Fig. 4 and cure time is tabulated in Table 3. In the absence of $\mathrm{ZnO}$, the curing is extremely slow in the sample SBWZ and modulus is also lowest. The optimum cure time is faster with synthesized nano- $\mathrm{ZnO}$ samples by complex formation with acceleration compared to the reference one. $\mathrm{ZnO}$ helps in producing vulcanization precursor, hence faster curing can be observed in the presence of $\mathrm{ZnO}$ [29]. Due to decrease in particle size of $\mathrm{ZnO}$, the area of contact increases which helps to react better with accelerator. This leads to the generation of vulcanization precursor quicker. It results in a faster curing rate and lower cure time. Fastest curing can be seen with the use of organo-coated $\mathrm{ZnO}, \mathrm{Z4}$, followed by Z5. Due to the presence of long-chain organic PEG molecules, it has more compatibility with elastomeric matrix leading to better dispersion. The curing reaction is not affected and slowed down in the presence of $\mathrm{Z} 4$ at lower dose, i.e., 0.5 and $1.5 \mathrm{phr}$. It indicates that dispersion of $\mathrm{ZnO}$ plays a major role in efficient vulcanization, rather 
Fig. 2 TEM image of the sample a Z1, b Z2, c Z3, d Z4, e $\mathrm{Z} 5$ and $\mathbf{f} \mathrm{Z} 6$
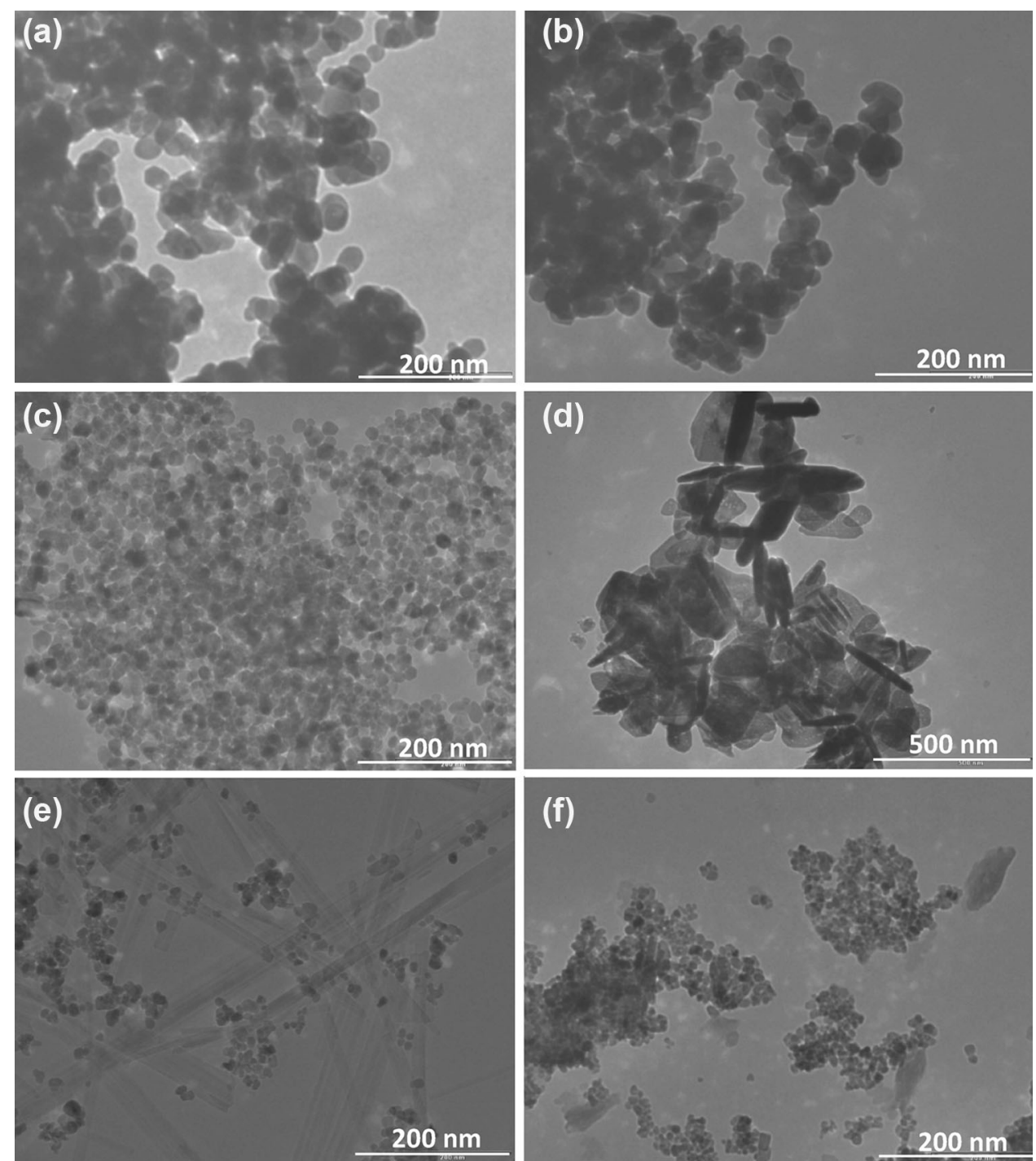

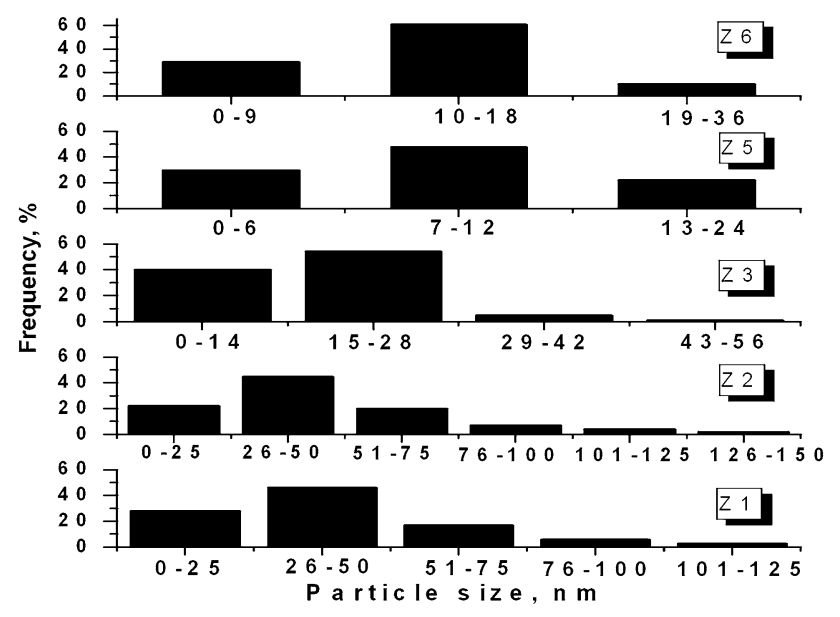

Fig. 3 Particle size distribution curves of different $\mathrm{ZnO}$ samples

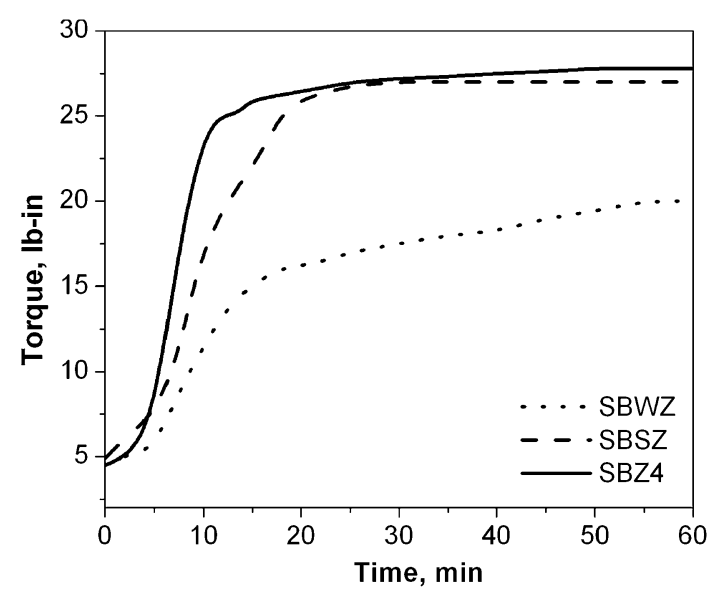

Fig. 4 Representative rheographic profiles of SBR/BR blends containing different $\mathrm{ZnO}$ samples 
than higher loading of $\mathrm{ZnO}$. The difference in minimum $\left(M_{\mathrm{L}}\right)$ and maximum $\left(M_{\mathrm{H}}\right)$ torque value, $\left[\Delta S=\left(M_{\mathrm{H}}-\right.\right.$ $\left.M_{\mathrm{L}}\right)$ ] has increased in SBR/BR blend with the use of synthesized nano- $\mathrm{ZnO}$ compared to that of reference $\mathrm{ZnO}$

Table 3 BET value of different nano-ZnO samples

\begin{tabular}{lcl}
\hline Sample & Surface area $\left(\mathrm{m}^{2} \mathrm{~g}^{-1}\right)$ & Pore volume $\left(\mathrm{cm}^{3} \mathrm{~g}^{-1}\right)$ \\
\hline Reference ZnO, SZ & 5 & 0.025 \\
$\mathrm{Z1}$ & 18 & 0.123 \\
$\mathrm{Z2}$ & 11 & 0.084 \\
$\mathrm{Z3}$ & 39 & 0.110 \\
$\mathrm{Z4}$ & 5 & 0.039 \\
$\mathrm{Z5}$ & 104 & 0.230 \\
Z6 & 55 & 0.110 \\
\hline
\end{tabular}

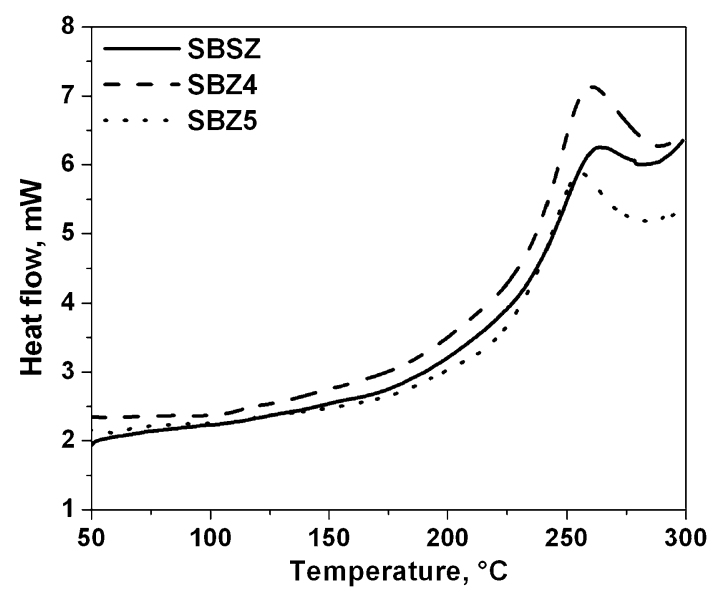

Fig. 5 DSC curves of different $\mathrm{ZnO}$ containing SBR/BR compounds depicting dynamic curing based sample. Increased $\Delta S$ indicates resistance to polymer chain mobility [30]. Due to the formation of increased crosslinks, chain mobility is restricted which will lead to higher crosslink density. In the case of Z5, the template, sepiolite which is fibrous clay with high aspect ratio, can help in better distribution of $\mathrm{ZnO}$ particles. As mentioned earlier, the area of contact increases in such case and helps in generation of vulcanizing precursors faster. These nano$\mathrm{ZnO}$ samples impart better co-curing of both the rubbers in SBR/BR blend.

The presence of very little amount of magnesium in Z6 ( $\mathrm{Zn}: \mathrm{Mg}$ 90:1, as revealed from ICP-OES analysis) has visible impact on cure properties. It increases the optimum cure time but at the same time it also increases $\Delta S$ values. It produces maximum number of crosslinks but at a slower rate.

Most encouraging effect of synthesized nano- $\mathrm{ZnO}$ on curing can be observed in the presence of filler. Optimum cure time is lowered by 7-10 $\mathrm{min}$ in the case of synthesized nano- $\mathrm{ZnO}$ containing compounds compared to the reference $\mathrm{ZnO}$ based compound (which even contains higher dose of $\mathrm{ZnO}$ ). Thus, $\mathrm{ZnO}$ nanoparticles can help in the reduction of the production cycle and also in minimizing the Zn-pollution due to lower dose.

Cure behavior in dynamic condition is shown in the representative plots (Fig. 5). The results differ slightly from static curing, though Z4 shows most efficient crosslinking activities $\left(\Delta H=123.70 \mathrm{Jg}^{-1}\right)$ in dynamic curing, too (Table 4).

\section{Physico-mechanical properties of different rubber composites}

The nano-ZnO particles may also act as nano-fillers. Physico-mechanical properties of different rubber composites
Table 4 Cure properties of different elastomeric compounds

\begin{tabular}{lllll}
\hline Sample & Cure time, $t_{90}(\min )$ & $M_{\mathrm{H}}(\mathrm{lb}-\mathrm{in})$ & $M_{\mathrm{L}}(\mathrm{lb}-\mathrm{in})$ & $M_{\mathrm{H}}-M_{\mathrm{L}}(\mathrm{lb}-$ in $)$ \\
\hline SBWZ & $38.2(0.08)^{\mathrm{a}}$ & $20.28(0.07)$ & $3.97(0.14)$ & 16.31 \\
SBSZ & $18.5(0.10)$ & $27.01(0.10)$ & $4.87(0.13)$ & 22.14 \\
SBZ1 & $17.0(0.09)$ & $27.43(0.15)$ & $3.62(0.09)$ & 23.81 \\
SBZ2 & $16.9(0.07)$ & $28.03(0.20)$ & $3.72(0.10)$ & 24.31 \\
SBZ3 & $16.4(0.12)$ & $28.35(0.04)$ & $4.12(0.08)$ & 24.23 \\
SBZ4 & $12.9(0.07)$ & $27.85(0.13)$ & $4.05(0.02)$ & 23.80 \\
SBZ5 & $13.0(0.11)$ & $28.74(0.09)$ & $4.48(0.04)$ & 24.46 \\
SBZ6 & $19.2(0.08)$ & $30.16(0.07)$ & $5.03(0.05)$ & 25.13 \\
$0.5 S B Z 4$ & $12.2(0.07)$ & $27.93(0.13)$ & $4.42(0.04)$ & 23.51 \\
$1.5 S B Z 4$ & $12.5(0.10)$ & $27.87(0.14)$ & $4.43(0.03)$ & 23.44 \\
SBSZF & $25.3(0.07)$ & $35.83(0.21)$ & $6.95(0.12)$ & 28.88 \\
SBZ4F & $15.6(0.09)$ & $43.76(0.23)$ & $8.01(0.14)$ & 35.75 \\
SBZ5F & $18.0(0.04)$ & $39.88(0.24)$ & $7.45(0.11)$ & 32.43
\end{tabular}

${ }^{a}$ Values in parentheses are standard deviations 
are reported in Table $5 . \mathrm{Z} 2, \mathrm{Z} 3, \mathrm{Z} 4$ and $\mathrm{Z} 5$ containing SBR/BR blend based nanocomposites show better tensile strength and hardness compared to the reference one. The sample containing organo-coated $\mathrm{ZnO}(\mathrm{Z} 4)$ displays highest tensile strength. This is ascribed to the better compatibility and in turn better dispersion of $\mathrm{Z} 4$ in the rubber matrix. This leads to better curing as observed in the previous experiments and higher value of volume fraction of rubber $\left(V_{\mathrm{r}}\right)$ as well as crosslink density. Z4 imparts highest reinforcement. From these results it can be concluded that dispersion of nanoparticles plays the major role in enhancement of properties.

Though lower filler loading maintains the cure properties unaltered (as observed in 0.5SBZ4 and 1.5SBZ4) but it does not provide the same amount of reinforcement as

Table 5 Dynamic cure properties of different elastomeric compounds

\begin{tabular}{llc}
\hline Sample & $T_{\max }\left({ }^{\circ} \mathrm{C}\right)$ & $\Delta H\left(\mathrm{~J} \mathrm{~g}^{-1}\right)$ \\
\hline SBSZ & 261 & 63.66 \\
SBZ2 & 261 & 88.39 \\
SBZ3 & 262 & 81.06 \\
SBZ4 & 258 & 123.70 \\
SBZ5 & 254 & 86.58 \\
SBZ6 & 260 & 92.92 \\
\hline
\end{tabular}

3 phr loading. Tensile strength, 100\% modulus and hardness decrease with decreasing $\mathrm{ZnO}$ loading.

Nano-ZnO containing compounds show slightly better properties than those of reference $\mathrm{ZnO}$ based compound. Z5 based compound exhibits highest overall properties. This may be due to some synergistic effect between nanofiller, sepiolite and conventional filler, carbon black [31]. The similar kind of effect has also been studied in our previous study using mesoporous silica as reinforcing filler in the poly butadiene rubber matrix in the presence of nanoclays, silica and carbon black [32].

\section{Morphology}

The topographical images of SEM shown in Fig. 6 of different SBR/BR blend either having synthesized nano$\mathrm{ZnO}$ or standard rubber grade- $\mathrm{ZnO}$ is studied to evaluate the extent of dispersion of $\mathrm{ZnO}$ within the rubber blend. The black phase implies the rubber matrix, whereas the white dot is the reflection of $\mathrm{ZnO}$ particles. In SEM images of SBSZ (Fig. 6a), some agglomeration of $\mathrm{ZnO}$ nanoparticles in the form of white dot can be seen. Figure $6 \mathrm{~b}$ indicates that uniform dispersion of nano- $\mathrm{ZnO}$ occurs throughout the entire blend in comparison to standard rubber grade-ZnO (Fig. 5a). In case of SBZ4 (Fig. 6c), the rod-like structure as observed in TEM photo-micrographs (Fig. 2d) can also be seen. However, in the image of sepiolite based synthesized nano-ZnO (Fig. 5d), the homogenous distribution of $\mathrm{ZnO}$ with minimum particle
Fig. 6 SEM images of a SBSZ, b SBZ3, c SBZ4 and d SBZ5
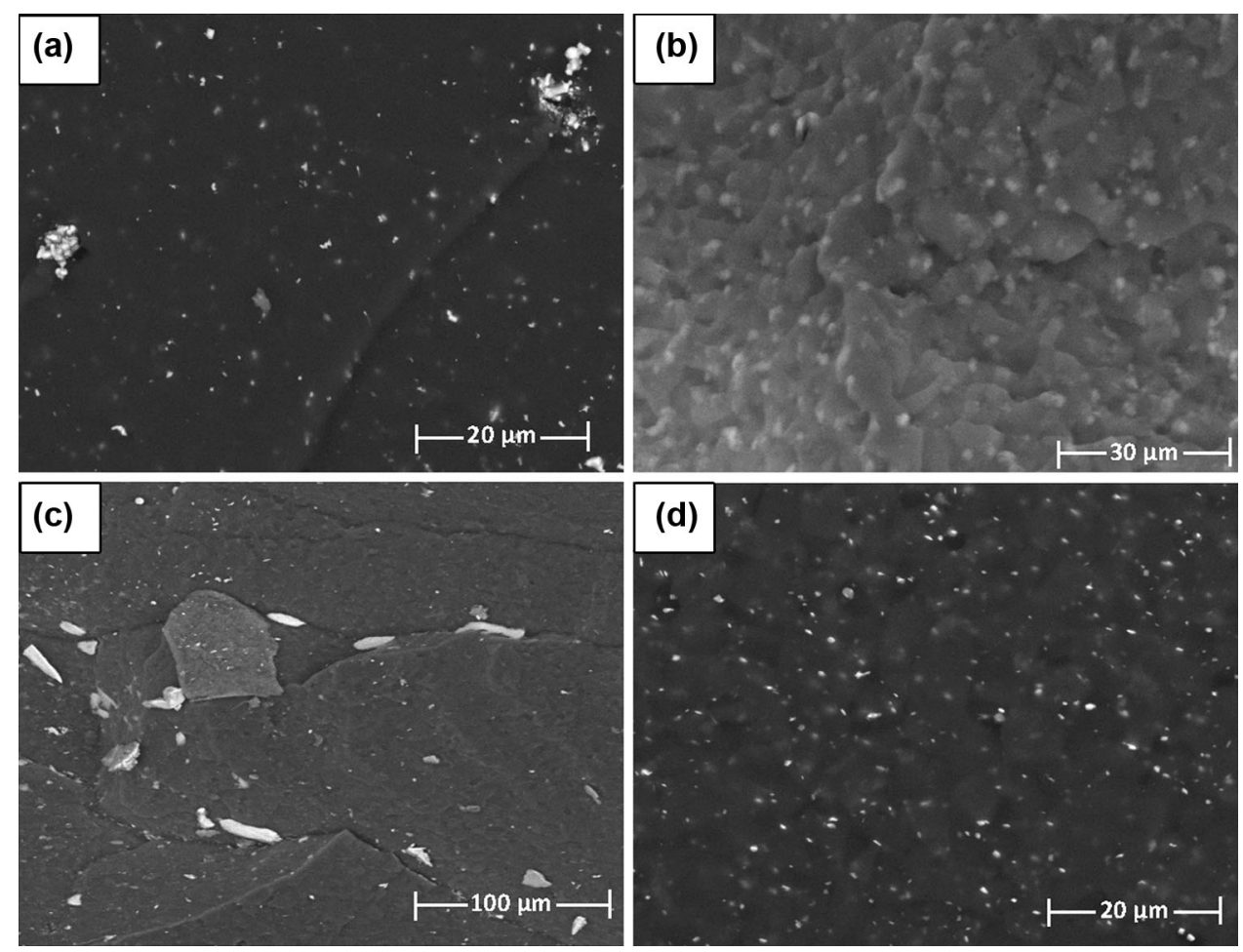
Table 6 Physico-mechanical properties of different rubber composites

\begin{tabular}{lllllll}
\hline Sample & $\begin{array}{l}\text { Tensile strength } \\
(\mathrm{MPa})\end{array}$ & $\begin{array}{l}\text { Modulus at 100\% } \\
\text { elongation }(\mathrm{MPa})\end{array}$ & $\begin{array}{l}\text { Elongation at } \\
\text { break }(\%)\end{array}$ & $\begin{array}{l}\text { Hardness } \\
(\text { shore A) }\end{array}$ & $V_{\mathrm{r}}$ & $\begin{array}{l}\text { Crosslink } \\
\text { density } \times 10^{-5} \mathrm{~mol} \mathrm{~cm}^{-3}\end{array}$ \\
\hline SBWZ & $1.73(0.02)^{\mathrm{a}}$ & $0.70(0.02)$ & $445(10)$ & $37(0.3)$ & $0.112(0.003)$ & $2.50(0.01)$ \\
SBSZ & $1.89(0.02)$ & $0.84(0.03)$ & $310(12)$ & $41(0.2)$ & $0.165(0.002)$ & $6.31(0.02)$ \\
SBZ1 & $1.82(0.03)$ & $0.73(0.03)$ & $320(15)$ & $43(0.3)$ & $0.164(0.002)$ & $6.22(0.03)$ \\
SBZ2 & $2.12(0.03)$ & $0.78(0.04)$ & $335(18)$ & $43(0.4)$ & $0.168(0.003)$ & $6.60(0.01)$ \\
SBZ3 & $2.07(0.04)$ & $1.09(0.03)$ & $265(22)$ & $45(0.3)$ & $0.164(0.004)$ & $6.22(0.01)$ \\
SBZ4 & $2.54(0.01)$ & $1.05(0.02)$ & $295(14)$ & $44(0.4)$ & $0.171(0.002)$ & $6.90(0.02)$ \\
SBZ5 & $2.05(0.05)$ & $1.07(0.02)$ & $250(18)$ & $45(0.2)$ & $0.167(0.002)$ & $6.50(0.03)$ \\
SBZ6 & $1.90(0.03)$ & $0.90(0.03)$ & $280(12)$ & $46(0.1)$ & $0.169(0.003)$ & $6.70(0.04)$ \\
$0.5 S B Z 4$ & $1.61(0.02)$ & $0.72(0.02)$ & $335(10)$ & $37(0.3)$ & $0.165(0.002)$ & $6.31(0.02)$ \\
$1.5 S B Z 4$ & $2.15(0.01)$ & $0.94(0.03)$ & $290(17)$ & $41(0.2)$ & $0.169(0.004)$ & $6.70(0.01)$ \\
SBSZF & $14.30(0.5)$ & $1.62(0.02)$ & $560(09)$ & $61(0.1)$ & $0.187(0.005)$ & $8.65(0.04)$ \\
SBZ4F & $14.84(0.2)$ & $1.67(0.01)$ & $565(08)$ & $63(0.2)$ & $0.191(0.005)$ & $9.13(0.03)$ \\
SBZ5F & $15.24(0.3)$ & $1.82(0.01)$ & $645(10)$ & $63(0.3)$ & $0.190(0.007)$ & $9.01(0.02)$ \\
\hline
\end{tabular}

${ }^{a}$ Values in parentheses are standard deviations

size is observed (as seen in TEM images too) (Fig. 2e). As a result, the improvement of mechanical properties of the SBR/BR blend can be noticed (Table 5). From the SEM images, it can be distinguished that the distribution of $\mathrm{ZnO}$ in the SBR/BR blend is comparatively better for nano- $\mathrm{ZnO}$ which in turn is reflected in mechanical properties (Table 6).

\section{Conclusions}

Six different nano-ZnO samples were synthesized by both high temperature calcination and low-temperature hydrolysis methods. All the samples had wurtzite structure and average particle size in the ' $\mathrm{nm}$ ' range. $\mathrm{ZnO}$, grown on sepiolite nanofiber, showed smallest particle size as well as highest surface area. PEG-coated $\mathrm{ZnO}$ nanoparticles were rod-like in structure. Effect of these nano- $\mathrm{ZnO}$ samples on cure properties of SBR/BR blends was studied by both static and dynamic curing methods. PEG-coated nano-ZnO sample exhibited maximum positive impact on cure properties. For PEG-coated $\mathrm{ZnO}$, cure properties remained unaltered even at lower loadings ( 0.5 and $1.5 \mathrm{phr})$ of $\mathrm{ZnO}$. From the observed results, it can be concluded that the cure properties are governed primarily by dispersion of cureactivator rather than its concentration and morphology. Nano-ZnO can act as nanofiller also. The sample containing organo-coated $\mathrm{ZnO}$ (Z4) displays highest tensile strength due to better compatibility and in turn better dispersion of $\mathrm{Z} 4$ in the rubber matrix. Dosing (of nano- $\mathrm{ZnO}$ ) lower than $3 \mathrm{phr}$ could not impart any reinforcement. Topographical images of SEM study indicates more uniform dispersion of synthesized nano-ZnO over standard rubber grade- $\mathrm{ZnO}$ within rubber blend and this fact account for better mechanical properties. Nano-ZnO imparted faster curing even in the presence of conventional filler, carbon black compared with reference $\mathrm{ZnO}$. Thus, the use of $\mathrm{ZnO}$ nanoparticles can provide faster curing, better reinforcement at lower dosing compared to standard $\mathrm{ZnO}$, which can lead to shorter production cycles and less zinc pollution.

Acknowledgements The authors are highly thankful to Ms. Hetal Patel and Mr. Chirag S. Shah for their kind cooperation. Authors are grateful to Reliance Industries Ltd. for its consent to publish this work. Authors are also thankful to colleagues from catalyst, analytical and elastomer groups of RTG-VMD for their support.

Open Access This article is distributed under the terms of the Creative Commons Attribution 4.0 International License (http://creative commons.org/licenses/by/4.0/), which permits unrestricted use, distribution, and reproduction in any medium, provided you give appropriate credit to the original author(s) and the source, provide a link to the Creative Commons license, and indicate if changes were made.

\section{References}

1. Frohlich J, Niedermeier W, Luginsland HD (2005) The effect of filler-filler and filler-elastomer interaction on rubber reinforcement. Compos A 36:449-460

2. Schuater RH (2001) The challenge a head-new polymer filler systems. Rubber World 224:24-28

3. Morton M (1959) Introduction to rubber technology. Reinhold Publishing Corporation, New York

4. Councell TB, Duckenfield KU, Landa ER, Callender E (2004) Tire-wear particles as a source of zinc to the environment. Environ Sci Technol 38:4206-4214

5. Smolders E, Degryse F (2002) Fate and effect of zinc from tire debris in soil. Environ Sci Technol 36:3706-3710 
6. Heideman G, Noordermeer JWM, Datta RN, Baarle BV (2005) Effect of metal oxides as activator for sulphur vulcanisation in various rubbers. Kautschuk Gummi Kunststoffe 58:30-42

7. Basu D, Das A, Stockelhuber KW, Wagenknecht U, Heinrich G (2014) Advances in layered double hydroxide (LDH)-based elastomer composites. Prog Polym Sci 39:594-626

8. Sahoo S, Maiti M, Ganguly A, George JJ, Bhowmick AK (2007) Effect of zinc oxide nanoparticles as cure activator on the properties of natural rubber and nitrile rubber. J Appl Polym Sci 105:2407-2415

9. Sahoo S, Bhowmick AK (2007) Influence of $\mathrm{ZnO}$ nanoparticles on the cure characteristics and mechanical properties of carboxylated nitrile rubber. J Appl Polym Sci 106:3077-3083

10. Sahoo S, Kar S, Ganguly A, Maiti M, Bhowmick AK (2008) Synthetic zinc oxide nanoparticles as curing agent for polychloroprene. Polym Polym Compos 16:193-198

11. Sabura Begum PM, Yusuff KKM, Joseph R (2008) Preparation and use of nano zinc oxide in neoprene rubber. Int J Polym Mater 57:1083-1094

12. Sabura Begum PM, Joseph R, Yusuff KKM (2008) Preparation of nano zinc oxide, its characterization and use in natural rubber. Prog Rubber Plast Recycl 24:141-148

13. Przybyszewska M, Zaborski M (2009) New coagents in crosslinking of hydrogenated butadiene-acrylonitrile elastomer based on nanostructured zinc oxide. Compos Interfaces 16:131-141

14. Przybyszewska M, Zaborski M (2010) Effect of ionic liquids and surfactants on zinc oxide nanoparticle activity in crosslinking of acrylonitrile butadiene elastomer. J Appl Polym Sci 116:155-164

15. Przybyszewska M, Zaborski M (2009) The effect of zinc oxide nanoparticle morphology on activity in crosslinking of carboxylated nitrile elastomer. Express Polym Lett 3:542-552

16. Guzman M, Reyes G, Agullo N, Borros S (2011) Synthesis of Zn/ $\mathrm{Mg}$ oxide nanoparticles and its influence on sulfur vulcanization. J Appl Polym Sci 119:2048-2057

17. Heideman G, Datta RN, Noordermeer JWM, Van Baarle B (2005) Influence of zinc oxide during different stages of sulfur vulcanization. Elucidated by model compound studies. J Appl Polym Sci 95:1388-1404

18. Kim I, Kim W, Lee D, Kim W, Bae J (2010) Effect of nano zinc oxide on the cure characteristics and mechanical properties of the silica-filled natural rubber/butadiene rubber compounds. J Appl Polym Sci 117:1535-1543
19. Jincheng W, Yuehui CJ (2006) Application of nano-zinc oxide master batch in polybutadiene styrene rubber system. J Appl Polym Sci 101:922-930

20. Maiti M, Vaghasia A, Jasra RV (2012) Low-temperature synthesis of nano-to-submicron size organo-zinc oxide and its effect on properties of polybutadiene rubbe. J Appl Polym Sci 124:2857-2866

21. Wang J, Chen Y (2006) Application of nano-zinc oxide master batch in polybutadiene styrene rubber system. J Appl Polym Sci 101:922-930

22. Qi JY, Wu LX, Zhuo DX (2014) Preparation and properties of BR/SBR blends using surface-modified nano zinc oxide". Adv Mater Res 910:101-104

23. Sridevi D, Rajendran KV (2009) Synthesis and optical characteristics of $\mathrm{ZnO}$ nanocrystals. Bull Mater Sci 32:165-168

24. Aneesh PM, Jayaraj MK (2010) Red luminescence from hydrothermally synthesized Eu-doped $\mathrm{ZnO}$ nanoparticles under visible excitation. Bull Mater Sci 33:227-231

25. Gundert F, Wolf BA (1989) Solvents and non-solvents for polymers. In: Brandrup J, Immergut EM (eds) Polymer handbook, 3rd edn. Wiley, New York, VII, pp 173-182

26. Bhattacharyya S, Gedanken A (2008) A template-free, sonochemical route to porous $\mathrm{ZnO}$ nano-disks. Microporous Mesoporous Mater 110:553-559

27. Yalcin H, Bozkaya O (1995) Sepiolite-palygorskite from the Hekimhan region clay. Clay Miner 43:705-717

28. Monshi A, Foroughi MR, Monshi MR (2012) Modified Scherrer equation to estimate more accurately nano-crystallite size using XRD. World J Nano Sci Eng 2:154-160

29. Blow CM, Hepburn C (1982) Rubber technology and manufacture. Butterworth Scientific, London

30. Shamugharaj AM, Bae JH, Lee KY, Noh WH, Lee SH, Rye SH (2007) Physical and chemical characteristics of multiwalled carbon nanotubes functionalized with aminosilane and its influence on the properties of natural rubber composites. Comp Sci Technol 67:1813-1822

31. Maiti M, Sadhu S, Bhowmick AK (2005) Effect of carbon black on properties of rubber nanocomposites. J Appl Polym Sci 96:443-451

32. Maiti M, Basak GC, Srivastava VK, Jasra RV (2016) Mesoporous silica reinforced polybutadiene rubber hybrid composite. Int J Ind Chem 7:131-141 